\title{
Las afinidades electivas entre el arte y la estética
}

\author{
JOSÉ LUIS MOLINUEVO \\ Universidad de Salamanca
}

\section{LAS AFINIDADES ELECTIVAS Y EL ESTETICISMO}

Decía goethe en Las afinidades electivas que éstas sólo son interesantes si producen separaciones. Como es sabido, las afinidades electivas se refieren a procesos químicos en los que dos sustancias unidas se separan debido a la intervención de una tercera que actúa como disolvente. En este caso, la colaboración existente entre arte y estética se ha visto enturbiada por la aparición de un tercero, los intereses (de diverso tipo) que han confundido a ambas. Una de las causas me parece estar en lo que podía denominarse -parafraseando a Danto y marcando distancias respecto a sus planteamientos- como el abuso de la estética. Se podría tener en cuenta este hecho para, haciendo de la necesidad virtud, evitar confusiones y plantear una fructífera colaboración.

El abuso de la estética se conoce como esteticismo, y consiste en reducirla a mero instrumento para sensibilizar ideas filosóficas, éticas, políticas y religiosas. También para hacer atractivos los productos de mercado en la publicidad. El común denominador de los diversos esteticismos tiene como base la separación entre entendimiento y sentimiento y la reducción de la estética a este último. El movimiento contrario al esteticismo subraya, por el contrario, el valor cognitivo de la estética. Es decir, que mediante la unión de entendimiento y sentimiento en la experiencia estética llegamos a un conocimiento, ciertamente distinto, pero conocimiento al fin y al cabo, de los objetos. Este tipo de conocimiento estético viene definido desde sus orígenes como un saber estar en el espacio y tiempo concretos en que nos ha tocado vivir. Quien lo posee es una persona con gusto. Los objetos pueden ser muy diversos, pues la estética no tiene objeto propio sino que es un modo de ir a ellos, de tener experiencia de ellos. Cualquier cosa puede ser objeto de una experiencia estética y cualquiera puede tenerla. Pero eso no significa que todas valgan lo mismo, ni que todos estén igualmente capacitados. La formación de criterios estéticos es el objetivo de un proceso de ilustración estética, del individuo como ciudadano. 
Desde esta perspectiva, el esteticismo es fruto de una confusión (interesada) sobre la naturaleza y funciones de la estética. Un nuevo episodio de este fenómeno ha tenido lugar a finales del siglo XX con motivo de una polémica de la posmodernidad tardía en torno al arte contemporáneo. Es una polémica desarrollada a finales del siglo pasado especialmente en Francia y que ahora se sirve, quizá no por casualidad, y un tanto recalentada, en España. A título de inventario diré que los resultados no pueden ser más desoladores: tiene poco que ver con el arte contemporáneo en su conjunto y variedad y demuestra, una vez más, la inadecuación entre la práctica del arte y la reflexión en torno a él. Frente a los relatos del Gran Arte, ya sea clásico o moderno, se proclama un cierto escepticismo teórico en los criterios y un relativismo en los juicios. Se renuncia a definir el arte contemporáneo, pero no a juzgarlo y a establecer criterios, por más que sean locales, que permiten fundamentar la elección y decisión expresada en esos juicios.

Ahora bien, ¿de qué tipo de criterios y juicios estamos hablando? La sorpresa es que no suele tratarse de criterios y juicios artísticos, como cabía esperar, sino estéticos. ¿Acaso son lo mismo? ¿Basta con los criterios estéticos para formular juicios artísticos? Son preguntas que habrá que examinar más detenidamente, y también la posibilidad de ver cuál es la relación, no excluyente y de colaboración, entre ambos. En todo caso, y para evitar «tensiones», quizá fuera conveniente clarificar los términos de la polémica, «Estética y Arte», llamando de entrada la atención por un planteamiento en singular para contenidos tan plurales en cada uno de los ámbitos. Y es que, efectivamente, cuando se citan ejemplos de las artes se suelen referir a la pintura, no mucho a la escultura, algunas veces a la arquitectura, pero el resto -como por ejemplo, las artes visuales- no suelen aparecer.

Otro de los resultados llamativos de la polémica es su incidencia política ya que, se subraya, el pluralismo estético se corresponde con el espíritu de las democracias liberales. Y, habría que añadir, a pleno gusto de las instituciones políticas de distinto signo. Pues no en vano esta ideología postmoderna, de escepticismo y relativismo moderados, ha sido considerada hoy día como la ideología cómoda al poder en las sociedades democráticas, poder que ha mutado sus estrategias para optimizar, no abdicar de su ejercicio. Los posmodernos rechazan teóricamente todas las imposiciones pero aspiran a estar en todos los sitios. Situación en el terreno del arte que Rochlitz caracterizó irónicamente con dos palabras: «entre la subversión y la subvención». Y de la que ellos, también irónicamente, han hecho su bandera.

La supuesta polémica entre arte y estética, en el fondo, tiene como protagonistas a personas que se dedican a la estética y al arte y que tienen intereses comunes, a menudo enfrentados, en la gestión del arte. Sorprende la ausencia en ella de los artistas y del público, casi unos convidados de piedra. Pero por eso 
no menos aquejados de un evidente malestar en torno al arte contemporáneo, malestar, repito, no institucional. La polémica teórica y el malestar institucional no siempre coinciden, aunque sí se detecta una evidente incomodidad ciudadana, patente no ya en el rechazado airado, sino en las opiniones razonadas que han sido vertidas por expertos y no expertos en los medios de comunicación.

Este podía ser el preludio, no de un resumen de la polémica, sino de unas reflexiones de los temas planteados en torno a ella. Porque el tema de la relación entre arte y estética es muy antiguo, y se solía plantear en singular, al menos hasta mediados del siglo XIX. El problema entre ambos, si es que lo hay, parece ser muy reciente.

\section{EL PROBLEMA}

Hay dos elementos que han sido decisivos en la configuración del problema: la separación categorial entre arte moderno y arte contemporáneo, que se suele ubicar al término de la Segunda Guerra Mundial, y la crisis de las estéticas de la vivencia, un residuo romántico a finales del XIX y comienzos del XX. Lo primero ha planteado cuestiones en torno a la identidad del arte contemporáneo, en sí mismo, y luego por la enorme ampliación del número de las artes. Y, respecto a lo segundo, el paso de las estéticas de la vivencia a las del conocimiento ha provocado una gran transformación en la estética, siendo una de los mejores antídotos contra el esteticismo. Otro hecho que hay que destacar es el llamado «giro al arte» que se da en la filosofía (especialmente en la generación del 14), confundiéndose a veces la Estética con la Teoría del arte o la Filosofía del arte. Aspecto éste poco tenido en cuenta en la polémica que ha enfrentado a las llamadas versiones especulativas y pragmáticas del arte. Contra lo que pueda parecer, no se trata sólo de una delimitación de campos debida a intereses teóricos o disciplinares. Lo que está realmente en juego es la situación social del arte contemporáneo y de la estética como supuesta fuente de legitimación teórica del mismo, no tanto a nivel académico, como por parte de los gestores mismos del arte. Esto último nos sitúa ante la paradoja de que ahora el arte no es más que arte, lo que al parecer siempre se había querido. $\mathrm{Y}$, sin embargo, tirios y troyanos se empeñan en meter por medio a la estética. ¿Cuál es la razón? Tratan, unos y otros, teóricos y gestores, a menudo en papeles intercambiables, de ofrecer algo más que arte porque es lo que se exige en el mercado del arte. Y esto es también esteticismo.

La situación no es nueva: durante siglos el arte simbólico y representativo tuvo la función estética de sensibilizar ideas morales, políticas, religiosas etc., y en el caso del «giro al arte», al Gran Arte, de servir como referente del pensamiento en la crisis de la filosofía. Supuestamente el arte conquistó su 
autonomía dejando de producir belleza y exponiendo verdad, más aún, incluso abandonó esto último quedando simplemente como actividad de quienes quieren dedicarse al arte, y no por ello intentar con cada obra salvar el universo o hacerse cargo de las hipotecas del pensamiento trascendental. Es posible que el arte consiguiera su autonomía, pero es cuestionable que al suceder esto la estética recobrara la suya, abocada a una nueva subordinación en este caso al arte contemporáneo como instancia legitimadora suya.

Este hecho parece incardinarse en un fatum de la estética. Desgraciadamente, el esteticismo está en su entraña misma. Desde sus comienzos la estética ha servido para sensibilizar ideas morales, políticas, religiosas, intereses económicos, con tanto éxito que hemos llegado al esteticismo actual. Hoy día no se vende nada, y de vender se trata, empezando por venderse, ya sea utópica o distópicamente, sin la estética. Esteticismo que, en realidad, es una servidumbre, pues tiene una dimensión social, y afirma que la sociedad misma, no sólo el arte, está estetizada. Y sirve a discursos globalizadores de dudosa validez teórica. Por ejemplo, los discursos sobre la sociedad del consumo, del espectáculo, la sociedad líquida, etc. No carecen de fundamento, hasta el momento en que se absolutizan, en que todo se ve bajo ese prisma, y además se hace de ello la característica esencial de la sociedad contemporánea. La denuncia del abuso acaba eliminando la posibilidad misma del uso.

Esta globalización del discurso pseudoestético no es casual. Máxime cuando se examinan los fundamentos del mismo, generalmente herederos más o menos cercanos de la dialéctica de la ilustración llevada a cabo por los frankfurtianos. Es la conocida crítica en clave de la industria cultural. Pero la raíz del fenómeno no está en una perversión de la Ilustración, sino que radica en el Romanticismo. Porque la estetización no es un fenómeno exclusivamente contemporáneo sino romántico, y está en relación estrecha con la obra de arte total. No significa sólo que haya triunfado sobre otros el punto de vista estético sobre lo real, sino que la realidad misma es estética. De ahí viene la referencia a lo económico y político como una de las formas que se convierte en la obra de arte total. Importa insistir en esto, pues la estetización no es una perversión de la Estética, sino que es una opción estética, que está en su entraña misma. Y, aunque sea doloroso reconocerlo, es el núcleo del programa sistemático más antiguo del idealismo alemán, en su pretensión de aunar todas las ideas, haciéndolas estéticas, en la de belleza, siendo así asequibles al pueblo. Esta es la quintaesencia de la publicidad, aspecto éste de gran calado en que no es posible detenerse ahora.

Tan sólo señalar que esto no implica, sino todo lo contrario, la ausencia de criterios, de aprender a ver en el caso del arte, de pensar con imágenes. Porque el mismo romanticismo, y de esto se habla poco, nace subrayando también la inevitable separación entre ética, estética, política, religión, de modo que la 
mayor potencia estética se suele conseguir en la ausencia de aquellas o, en la mayor parte de los casos, contra ellas. Schiller, como más tarde Büchner, advertirá que un dramaturgo no es un profesor de moral, ni un predicador, pero sí alguien que nos permite ver aspectos de nuestra existencia. Aprender, pues, a ver, a sentir. Esta es la verdadera orientación y no la pretensión idealista de prescribir lo que debemos ser y tenemos que hacer. Ciertamente supone una dimensión prepolítica y se refiere a la responsabilidad estética como ciudadanos. Y por ello apunta a la posible responsabilidad del artista, también como ciudadano.

\section{LAS PARADOJAS}

Fruto de ese doble planteamiento romántico, de crítica del esteticismo y promoción del mismo, la situación actual es cuando menos paradójica. Y así la polémica se centra aquí en reclamar para la estética una autonomía respecto a su supuesta servidumbre al arte, como instrumento de legitimación suyo. Pero una vez conquistada, se van al lado contrario, de tal modo, que acaba llevando a un triunfo de la estética sobre el arte, especialmente el arte contemporáneo, disuelto en el «estado gaseoso» de la «experiencia estética», como señala Michaud. Expresión esta última que ahora está cargada de ambigüedad por su dimensión esteticista. Lo que se acrecienta con el remedio propuesto, y en principio, de lo más recomendable: vuelta, pues, a la experiencia estética. El problema, y de ahí la perplejidad, es que luego no saben qué hacer con ella, y vuelven a configurar la experiencia estética casi con referencia exclusiva al arte. ¿Para qué, entonces, la supuesta polémica y la reivindicación de autonomía?

A esta paradoja se añade otra. Y es la necesaria crítica a la versión idealista y romántica del arte y, como herencia del siglo pasado, la denuncia de las famosas deshumanizaciones del arte, superación del idealismo etc. Pero, sin embargo, cuando se llega al arte contemporáneo, que respondería a esa necesidad de superarlas, parece volver a echárselas de menos. Es decir, cuando supone que el arte ya no es más que arte, entonces surge el descontento y se critica el que sólo sea eso, arte.

De modo que, y perdóneseme la malicia, la reivindicación de una autonomía de la estética respecto del arte para luego dedicarla nuevamente a la legitimación del arte, estableciendo criterios o emitiendo juicios estéticos / artísticos, parece tener mucho más que ver con la reivindicación de una autonomía de mercado en la gestión del arte, disfrazada eso sí de presupuestos teóricos, bastante endebles por cierto. Las supuestas tensiones entre ellos no son tanto de intereses desinteresados como de interés común: el mercado. 


\section{MERCADO Y CRÍTICA DE ARTE}

Con motivo de la última feria de Arco, su directora, Lourdes Fernández, señalaba que no hay un debate en torno al arte contemporáneo, al menos en España. Inmediatamente salió la queja de por qué, entonces, había suprimido los foros de debate en la Feria, donde se ejercitaban estéticos y gestores de arte. Pero su intervención apuntaba a uno de los elementos del problema en torno al tema que estamos analizando: ¿crisis del arte o crisis de la crítica de arte? Y ¿desde qué punto de vista? No del cuantitativo, desde luego, habida cuenta de la proporción de artistas y de críticos que hay por kilómetro cuadrado en España.

Señalaba, más bien, Lourdes Fernández un hecho extraño, y es que se critica el cine, el teatro, la ópera, la literatura, la arquitectura, en los suplementos culturales, revistas especializadas y una crítica puede incidir en el éxito o fracaso de la obra. No parece suceder así con el arte. Cuando se hace una crítica en una revista, se escribe el texto de un catálogo, el tono es generalmente laudatorio. En este punto se es inflexible, y las razones del arte consisten en que la gente no se da a razones. Del mismo modo, cuando se entra en un museo de arte contemporáneo, se da por sentado que allí hay arte, pero no se pregunta si es buen o mal arte. Cabe argüir que la palabra Arte lleva anexo inevitablemente un juicio de valor. Esto no es del todo exacto, pues en unas artes sí ocurre, pero otras no necesariamente. De ahí la importancia de hablar de «Artes» en plural.

La referencia a la crisis de la crítica permite observar un contraste entre la pujanza del arte contemporáneo y el descrédito de sus agentes de legitimación debido, fundamentalmente, no a un desacuerdo con sus criterios estéticos, sino a la presumible ausencia de los mismos, o, y es el caso que vamos a examinar aquí, al establecimiento de criterios no contemporáneos para juzgar al arte contemporáneo. Y ahí reside buena parte del problema. Que consiste, a mi juicio, en que se siguen utilizando criterios de legitimación románticos para un arte contemporáneo que ya no lo es. Aunque sea por una razón distinta de la que se aduce en las polémicas. Sin entrar a fondo ahora en detalles hermenéuticos sí que conviene mencionar, al menos, unos ejemplos referidos a la teoría especulativa del arte.

\section{LA TEORÍA ESPECULATIVA DEL ARTE}

Schaeffer ha denominado a esa tarea de legitimación que lleva a cabo la estética para el arte la «teoría especulativa del arte», tal como expone en su obra El arte en la época moderna. El análisis que hace se mueve en el ámbito de la lectura idealista del romanticismo. Es decir, que encuentra en el romanticismo la 
génesis de la teoría especulativa del arte, pero porque aplica al romanticismo la teoría especulativa del arte, y entonces la mayor parte del romanticismo queda fuera, por su reducción al alemán, al primer romanticismo, y porque casi no aparecen las otras artes, excepto la poesía. En concreto la poesía trascendental, que sirve de base a la concepción de la obra de arte total.

Según él, la teoría especulativa del arte consiste en que el arte releva a la filosofía de su misión: ser una revelación ontológica del ser. Este planteamiento romántico se prolongaría en el «giro al arte» que hemos mencionado y, una vez agotado éste, en la incursión de teóricos del arte provenientes del campo de la metafísica, de la ontología y la hermenéutica, autores de obras repletas de efectos especiales ontológicos. El problema con este planteamiento de Schaeffer es que estamos ante una visión esencialista y reductiva del romanticismo que explica poco del ayer y menos del hoy. Se lleva a cabo lo que podríamos denominar como una jibarización del romanticismo: lo «esencial» del mismo sería que duró cinco años y tuvo lugar en Jena. Al proceder así, no llegamos a entender la complejidad del romanticismo actual. Habría, pues, que cambiar de prisma porque no se trata tanto de poner de manifiesto la actualidad del romanticismo, como de partir del romanticismo de la actualidad. Lo que implicaría acometer una dialéctica del mismo basada en esta nueva perspectiva.

Dialéctica que se extiende a la privilegiada relación entre arte y filosofía que, como ha señalado acertadamente Aumont, no es lo mismo que la de arte y pensamiento. De hecho, en Heidegger (uno de los representantes de esa teoría especulativa según Schaeffer) el pensamiento del arte sólo tiene como objeto llegar al arte del pensamiento, a sus orígenes, traicionados luego por la filosofía. Sin olvidar que Heidegger rechaza la estética, (a favor del arte) como expresión de la subjetividad moderna. En él la poesía se convierte en modelo de un pensamiento meditante y no calculador, que tiene como referencia el Gran Arte de los griegos y una visión del arte contemporáneo que no suele ser moderna. Por lo que Schaeffer acierta nuevamente al subrayar que cierta forma de ver el arte ha ido ligada a la utopía del pensamiento, aunque, quizá, más por parte del pensamiento que del arte. ¿Quiere esto decir que no pueden ir unidos? Por supuesto que sí, el problema es que se pensaba que debían ir unidos. Y de ahí la postulada unión entre Arte y Verdad del siglo pasado: que el arte debía hacerse cargo de las hipotecas del pensamiento en forma de orientación y de compromiso social. Pero, ahora, cuando se habla de Arte, en realidad, se está hablando de arte contemporáneo.

\section{VI. ¿QUÉ SUCEDE CON EL ARTE CONTEMPORÁNEO?}

Me parece acertado el planteamiento de Aumont cuando precisa que decir que el arte contemporáneo es el que se hace hoy es una obviedad, pero dictada 
en el sentido de la historia, es decir, se asocia con lo nuevo, y revela el divorcio entre el gusto institucional con el de la época. Eso le lleva a concluir, y creo que no le falta razón que: «En términos estéticos, "el arte contemporáneo" no existe». El problema es que se confunde aquí arte moderno con arte contemporáneo, teniendo lugar en el primero ese divorcio del gusto, mientras que en el segundo puede darse perfectamente una adecuación al gusto institucional. De hecho, y parafraseando a Valéry, todo acaba en el museo (Sorbona).

Respecto a lo «nuevo» asociado al arte contemporáneo convendría destacar la estrecha unión que se da hoy entre arte y hermenéutica, muy bien analizada por Michaud. En este momento el arte es más hermenéutica que obra, experiencia que objeto. La herencia idealista en el arte ha pasado de la exposición de la Idea a la idea de la exposición. El punto de confluencia entre ambos es la hermenéutica. El discurso sobre el origen de la obra de arte se ha desplazado al del origen del discurso sobre la obra de arte y de su experiencia, es decir, del efecto, y de la recepción. También es cierto que el discurso sobre los efectos es lo que crea la obra que, en cuanto tal, desaparece, es un ejemplo, una ilustración del discurso literario referido al arte y que acaba por fagocitarlo.

Los museos son los lugares extremos de la hermenéutica y el turismo de arte. Se va a los museos de arte contemporáneo como se va al Zoo, con intención educativa, para contemplar especímenes reunidos y cuidados por expertos, de naturaleza incierta, pero que en todo caso no forman parte de la vida cotidiana, y que deben permanecer ahí. Pero esto último, en lugar de provocar problemas, forma parte de un acuerdo tácito entre la Institución y el público. Si la publicidad suministra belleza, el museo presenta cuidadas disonancias. Los dos son la cara de la misma moneda. Son los supermercados de trascendencia para «individualismo de masas». En este sentido sería precisa una desacralización del arte, de los museos como nuevas catedrales con salas como capillas, festoneadas con leyendas en forma de rótulos explicativos que con frecuencia hacen enrojecer por su retórica.

Los museos son un ejemplo de la difuminación entre alta y baja cultura, en el turismo cultural. No se eleva sino que se baja. La muestra está en la obsesión por el número de visitantes, la verdadera razón de todo. El éxito de los museos consiste en la respuesta atenuada a la necesidad de Gran Arte, que ya no hay en ellos. La pérdida del aura se ha convertido en aurática en la hermenéutica. Ésa es la herencia del romanticismo que se da en todos los ámbitos de la cultura a través de la llamada industria cultural. Esto crea la falsa universalización de la experiencia estética. La tesis de Michaud es que si antes sin arte no había experiencia estética, ahora sin experiencia estética no hay arte. En la época del triunfo de la estética el arte se desvanece en el estado gaseoso de la experiencia estética encarnada en el turista del arte.

Con ello sentenciaría el fin de la utopía del arte, que iba unida a la utopía de la comunidad estética de Kant y de Schiller. El arte ofrece un principio de 
comunicación estética, pero, en realidad, nadie está de acuerdo en nada. Todo el mundo tiene la certeza del carácter universalizable de su experiencia, pero nadie convence a nadie cuando hay desacuerdo. La comunidad estética no es, pues, más que un mito. Y la culpa la tendría una falsa democratización de la cultura (cuantitativa) que habría llevado a una democracia cultural (cualitativa). En esto estaría de acuerdo Michaud con Finkielkraut: el mundo como una blogsfera universal, una jaula de grillos, en que todos gritan y nadie se entiende. Por obra de la democratización de la cultura, la alta cultura naufraga en la baja cultura de la democracia cultural. Lo que nos llevará a la postre a plantear un tema interesante, como son las relaciones entre arte contemporáneo, estética y democracia. Para ello son muy útiles las sugerencias de un libro que sobresale por encima de la media en la polémica: Las razones del arte, de Gerard Vilar.

Ahora bien, la crítica realizada a estos autores no debería confundir respecto a la idoneidad de las direcciones a las que apuntan. Es el caso de Schaeffer con su tesis de que no hay objetos estéticos, sino conductas estéticas, que describe de forma muy sumaria en términos de intencionalidad. Las conductas tienen direcciones e intereses muy variables, y se explica su relación con lo artístico en la medida en que ambas constituyen su objeto. Pero no sólo lo artístico. De hecho, al comienzo de la estética, y como ejemplo, predomina el tema de la belleza natural sobre la artística y aún en teorías estéticas como la de Adorno, aparecen ambas desarrolladas.

Sin embargo, al final acaba predominando el objeto artístico en esa experiencia estética, quizá porque se ve desde el punto de vista de la comunicación. Y así ocurre en el caso de Michaud con su propuesta de la experiencia estética como una comprensión informada. Reúne a su manera una estética cognitiva de sentimiento y conocimiento, que hace del arte no un patrimonio de expertos, pero que sí requiere criterio y argumentación.

Ambas, la de Schaeffer y Michaud, son posturas kantianas: el objeto estético se constituye en la experiencia estética. El problema es cómo. Si antes se diferenció entre objeto estético y artístico, ahora se trataría de hacerlo con los criterios relativos a ambos. Y esto significa entrar en un tema, el de los criterios y juicios estéticos y el de los criterios y juicios artísticos. Mi tesis es que no iban unidos en su origen y que su origen mismo hace problemática su aplicación conjunta al arte contemporáneo.

\section{CRITERIOS Y JUICIOS ESTÉTICOS. El CONDICIONAMIENTO ÉTICO}

En la modernidad la experiencia estética se expresa en juicios de gusto que manifiestan el placer o disgusto producidos por las representaciones de los objetos. El objeto de la representación de esos juicios de gusto suelen ser 
más los objetos naturales que los artificiales. En todo caso, son subjetivos y no llevan un conocimiento del objeto. Pero sí que se observa un condicionamiento moral de los juicios estéticos en su origen.

En este contexto la referencia a la estética kantiana es inevitable. La dificultad estriba cuando se quiere hacer a la vez, y sin diferenciar, un ejercicio histórico y de actualización, es decir, cuando se evita el núcleo de la estética kantiana para hacerla mas «actual». Para ello se acude al famoso parágrafo 60 de la Crítica del juicio, (pero mutilándolo) a la hora de establecer la ilustración estética como estética de la comunicación y de la humanidad. Ahora bien, precisamente al final del parágrafo se explicita cómo la ilustración estética no es sino un capítulo de la ilustración moral. Ya que $1^{\circ}$, «el gusto, en el fondo, es una facultad de juzgar la sensibilización de las ideas morales». Que consiste en una receptividad para ellas de la que se deriva un placer que el gusto declara valedero para la humanidad en general. De lo que se desprende, $2^{\circ}$, «que la verdadera propedéutica para fundar el gusto es el desarrollo de ideas morales».

Desde esta perspectiva, la relación entre categorías estéticas y éticas queda así establecida: la belleza es un símbolo de la moralidad, y ésta es una propedéutica del gusto; a su vez, lo sublime es el indicio del sentimiento del ser sublime que nos ha creado a todos. El desconocimiento de este punto, o su dejarlo de lado, sin darse cuenta de la raíz del planteamiento, explica buena parte del esteticismo actual. Que tiene varios sentidos, pero consiste ahora en asociar por parte del crítico, gestor, o profesor de Estética unos valores trascendentes a una obra intrascendente, a que el arte es o da algo más que el arte. No tiene por qué creer en ello, probablemente no hay nada de ello en la obra, ni siquiera lo ha pretendido el artista, pero así lo exige el mercado de variado signo. Se decía en los postkantianos, que sin la cosa en sí no se podía entrar en la Crítica de la razón pura, pero con ella no se puede permanecer. Del mismo modo, sin los juicios estéticos no se puede entrar en la estética kantiana, pero con ellos no se puede permanecer tampoco.

En el período romántico se da, probablemente, el momento de mayor confluencia entre Arte y Estética hasta el punto de que las fronteras quedan difuminadas: en la obra de arte total la realidad tiene un carácter estético y eso es lo que se expresa en la obra de arte. En la época actual da la impresión de que, al igual que se confundía el objeto estético con el objeto artístico, ahora se confunde el criterio y juicio estético con el artístico. Y son dos cosas diferentes, que ciertamente confluyen cuando la Estética se ocupa de Arte.

En Estética, la experiencia estética no conlleva criterio o juicio estético, excepto cuando se trata de la comunicación. Y sólo en la versión ilustrada kantiana van unidos. Ahora bien, sorprende que sean precisamente los críticos de esa Ilustración los que de cara al arte contemporáneo mantienen criterios y juicios estéticos como criterios y juicios artísticos, si bien, en sentido posmoder- 
no, de estéticas de la buena voluntad, es decir, locales, de acuerdos, limitados etc., que oscilan entre la piadosa acción comunicativa o el más contundente decisionismo institucional.

Emitir un juicio artístico implica tomar la obra de arte, más precisamente, a cada obra de arte y a cada artista, como fin y no como medio. Significa atender a la técnica y al artista y no hacerlo depender de las ocurrencias del crítico. De las ocurrencias o de la atribución de una falsa trascendencia. En este sentido es llamativo que se insista en el carácter simbólico de las experiencias estéticas referidas al arte, cuando buena parte del arte contemporáneo ha dejado de ser simbólico, después de la crisis de la representación, y tiene un carácter autoreferente. Por lo que el crítico debe aprender el lenguaje de cada artista si quiere expresar un juicio sobre su obra. De lo contrario, lo que se están aplicando son criterios románticos de hermenéutica del arte, como acertadamente señalaba Schaeffer.

Sin embargo, la experiencia de este comienzo de siglo nos llevaría a matizar: la experiencia estética no es sólo de la comunicación. Por una parte, muchas experiencias estéticas quedan en la esfera del individuo y no son comunicadas, quizá las más. En segundo lugar, quizá tampoco la mejor expresión de la experiencia estética sean los juicios de gusto, como manifestación de placer o displacer ante algo. Hay un cierto narcisismo estético en ello, como se pone de manifiesto en el dicho de Theodor Lipps: el placer estético es el placer de sí mismo objetivado.

En conclusión, yo no veo una crisis del arte contemporáneo, tampoco de los criterios y juicios artísticos, siempre que se tome al arte como lo que es: nada más, - pero tampoco menos- que arte. Sin un juicio de valor en la palabra, pero con una responsabilidad en su ejercicio como ciudadanos. Se trataría, pues, de dar la voz a los artistas, como protagonistas, al público como usuario, y de acotar el narcisismo de algunos críticos y el poder omnímodo de ciertos gestores. No habría, entonces, que confundir un conflicto teórico, que a mi modo de ver no lo hay, con un conflicto de intereses de gestión de arte, que sí lo hay. Y en ese caso el Arte pide, y con razón, que se le deje en paz. Y la Estética también.

\section{ARTE, ESTÉTICA Y DEMOCRACIA}

Unas observaciones provisionales, a modo de coda, sobre las relaciones entre estética, arte y democracia. Todavía resuena (aunque no guste citarlo) el planteamiento de Benjamin de que a la estetización de la política en el fascismo responde el comunismo con la politización del arte. A la distancia, no parece hoy muy afortunado. Pero desde hace algún tiempo se hace patente la 
necesidad de replantear las relaciones entre estética, arte y sociedad. La duda es si ello es sinónimo y se solapa con la posible relación entre arte, estética y democracia.

La definición institucional del arte conviene tanto a las democracias como a las dictaduras. En las dos se consigue por diferentes vías (integración o represión) una neutralización del arte experimental. La introducción de «desórdenes estéticos» y artísticos es, pues, muy limitada en el arte contemporáneo, acentuándose el escepticismo que ya manifestara en este sentido Adorno. Por otra parte, el posible desorden estético no es necesariamente un desorden artístico y viceversa. Hay dos razones: la vinculación entre lo estético y lo artístico es casual, no causal, y tampoco tiene que haber un orden previo en los dos ámbitos.

La relación entre arte y sociedad no es la misma que entre arte y democracia. En esta última está mediada por el llamado «individualismo de masas». Si cualquiera es un artista, si cualquier cosa es una obra de arte y cualquiera es un crítico, entonces lo que se concluye es que cualquiera es o puede ser cualquiera. Pero un ciudadano no es un cualquiera. Es lo cualitativo no lo cuantitativo. Puede ser un voto en democracia, pero es una persona en sociedad. La democratización de la cultura (acceso y recepción) no es lo mismo que la democracia cultural. $\mathrm{El}$ arte no se vota. Los votos valen igual en política, pero las razones no, en el caso de que se den, (tanto por quienes las dan como por las que se dan) y es ahí donde entra en juego la cultura de los expertos, el filtro de los gestores y la decisión de los responsables políticos.

La explicación de la raíz de las analogías guarda una estrecha relación con la concepción simbólica del arte. En varios sentidos. En el trascendentalismo débil de la pragmática del arte la relación kantiana entre estética y moralidad se traslada a la de arte y democracia. La regulación del pluralismo político sería una propedéutica para el tratamiento de la pluralidad de opiniones en arte, bajo la que es posible un consenso. Sin embargo, la pragmática del arte va a la deriva entre el trascendentalismo débil de su fundamentación y el pragmatismo de sus beneficiarios; entre el esteticismo en sentido fuerte, de la sensibilización, y el de sentido débil, las estéticas edificantes.

A esto se añade que, como se ha señalado antes, la utopía de la comunicación de raíz kantiana tiene sus límites, pero en ella misma, sin necesidad de llegar al escepticismo actual. Basta con recordar los escritos programáticos de Kant sobre la Ilustración. Se postula que, siendo la razón única, su correcto ejercicio hará que coincidan las razones del soberano con las de los súbditos. Huelga decir que raramente sucede así. Pero el despotismo ilustrado en sentido fuerte tiene la respuesta en la excepción contemplada por Kant, en Federico el Grande, quien puede decir: razonad cuanto queráis, pero obedeced. O lo que de una forma más llana expresó Lewis Carroll en Alicia en el país de las maravi- 
llas, al señalar que no importa lo que significan las palabras sino quién manda. Este es el límite del procedimiento basado en las razones en la pragmática. Por una parte el diálogo y, por otra, la decisión. No son incompatibles: hoy día en el arte y la política el decisionismo adopta una pose dialogal.

Que el arte es comunicación se apoya también en la idea de que el arte es un lenguaje simbólico. La hibridación entre imagen y texto, especialmente en las artes no plásticas, descansa en la insuficiente educación en una cultura de la imagen. De ahí el recurso literario para algo no literario. Los residuos del giro al arte en el siglo pasado se muestran en la pretensión de que la obra de arte sea la expresión de pensamientos. Lo que no impide que se pueda hacer una filosofía del arte que exprese pensamientos profundos, tengan o no relación con el arte. Pero, entonces, junto al conocido reproche de Schlegel se exponen al de Heidegger: ni es arte, ni es filosofía, ni es pensamiento.

En conclusión. Tiene sentido hablar de una estética filosófica por contraste con la estética kantiana al reclamar para ella una dimensión cognitiva, pero las razones del arte, si las hay, no son las de la estética. La postura de Adorno sobre la filosofía y la estética como la transparencia del arte es hoy difícilmente sostenible, porque el arte no es una actividad inconsciente que deba hacerse consciente a través de un concepto ajeno. Y la estética sólo puede nutrir su reflexión no sobre, sino desde la creación artística. 